\title{
OS ASPECTOS SENSORIAIS DOS ESPAÇOS DE HOSPEDAGEM E O TURISMO DE EXPERIÊNCIA PARA TODOS: UMA RELAÇÃO NECESSÁRIA
}

\author{
Flávia Papini Horta \\ Graduação em Arquitetura e Urbanismo pela Escola de Arquitetura da UFMG; \\ aluna de especialização em Design Universal pela faculdade INAP. \\ fpapinihorta@gmail.com
}

\begin{abstract}
Heloísa Helena Couto
Graduação em Design de Ambientes pela Escola de Design da UEMG, especialista em Revitalização Urbana e Arquitetônica pela Faculdade de Arquitetura da UFMG, mestra em Ambiente Construído e Patrimônio Sustentável na Escola de

Arquitetura da UFMG.

hhcriar@yahoo.com.br
\end{abstract}

Resumo: Este artigo analisa a relação necessária entre os aspectos sensoriais do espaço, locais de hospedagens universais e turismo de experiência no atual cenário turístico brasileiro. Considera-se o viajante contemporâneo que, cansado de um cotidiano linear, busca não só lazer ou descanso, mas novos caminhos sensoriais, culturais e estéticos. Começa-se a pensar, então, como o espaço construído pode influenciar na criação dessas novas experiências. Os objetos e os espaços são fortes emissores de subsídios sensoriais e cada usuário é um receptor único de informações. $\mathrm{Na}$ união dessas afirmações, temos a combinação perfeita para um denso extrato de sensações. Além de possibilitar novas experiências por meio das informações do espaço, os aspectos sensoriais também são responsáveis pela criação de mapas mentais, presentes na imaginação humana. Para o desenvolvimento deste artigo foi feita inicialmente uma revisão de literatura. Em seguida, buscou-se conceituar cada tema aqui discutido e, logo após, considerar a afinidade entre eles a fim de provar a relação intrínseca entre as três temáticas. A partir dessa análise conclui-se que os aspectos sensoriais do espaço são ferramentas que maximizam o turismo de experiência. Também possibilitam a apreensão do espaço por qualquer usuário independentemente de ser uma pessoa com deficiência ou não, universalizando ao máximo os espaços de hospedagem.

Palavras-chave: design universal, espaços de hospedagem, turismo de experiência e aspectos sensoriais.

Abstract: This article analyzes the relation between the sensory aspects of the space, universal places of accommodation and tourism of experience of the current Brazilian tourism scenery. The contemporary traveler who, tired of a linear everyday, seeking not only leisure or rest, but new sensory, cultural and aesthetic paths. Starts to think, then, how the built environment can influence the creation of these new experiences. The objects and spaces are strong emitters of sensory information and 
each user as a single receiver of information. The union of these statements, we have the perfect combination for a dense extract of sensations. In addition to enabling new experiences through the information space, the sensory aspects are also responsible for creating mental maps present in human imagination. For the development of this article it was made initially a literature review. Next, we sought to conceptualize each topic discussed here and, soon after, to analyze the relationship between them in order to prove the intrinsic relationship between the three themes. From this analysis it is concluded that the sensory aspects of space are tools that maximize the tourism of experience. They also allow the seizure of space by any user regardless of being a disabled person or not, universalizing the most of hosting spaces.

Keywords: universal design, hosting spaces, experience tourism and sensorial aspects of space.

\section{INTRODUÇÃO}

A demanda por espaços universais, que possibilitem o adequado acesso de pessoas com deficiência, é uma questão que concerne ao modo contemporâneo humanista de analisar os ambientes. Há atualmente no cenário turístico brasileiro uma tendência a se pensar mais na acessibilidade dos espaços. Outro tema recorrente no meio acadêmico é o surgimento do conceito de turismo de experiência. A intenção deste artigo é mostrar a relação intrínseca que existe entre o turismo de experiência, locais de hospedagens universais e os aspectos sensoriais do ambiente. $\mathrm{O}$ viajante contemporâneo busca em seus roteiros alcançar novas experiências sensoriais, culturais e estéticas. Outro ponto importante a ser visto neste artigo é a capacidade que os espaços possuem de emitir informações aos usuários. Essas informações são recebidas e interpretadas por eles criando mapas mentais do local e, conseqüentemente, novas experiências. Buscar superar as barreiras físicas e sensoriais que o espaço pode oferecer se torna uma questão primordial para o profissional de design e arquitetura no momento de concepção do projeto. Com o objetivo de aplicar esse conceito de design universal ao da categoria turismo de experiência, observa-se uma necessidade de se pensar nos aspectos não físicos do espaço, ou seja, o campo do sensorial. Dentre tantos sentidos que o ser humano possui, a possibilidade de apreender o ambiente de várias maneiras pode se tornar uma experiência única ao usuário.

Este artigo busca defender a relação intrínseca que existe entre o turismo de experiência para todos e os aspectos sensoriais do ambiente. Para tanto foi feito inicialmente uma revisão de literatura a fim de conceituar os temas de maneira compendiada. Em seguida procura-se estabelecer a relação entre as leis municipais, estaduais e federais e o papel social do design universal nos espaços de turismo. À frente há uma breve análise do recente "Estudo do Perfil de Turistas - Pessoas com deficiência"1, publicado pelo Ministério do Turismo no final do ano de 2013. Em seguida busca-se compreender o significado dos aspectos sensoriais dos espaços. Finalmente, já com uma conceituação formada, é estabelecida a relação entre turismo de experiência para todos e os aspectos sensoriais do ambiente.

${ }^{1}$ MINISTÉRIO DO TURISMO, 2013. Estudo do perfil de turistas - Pessoas com Deficiência. Documento técnico, 2013. 


\section{DESENVOLVIMENTO}

A questão primordial levantada está na compreensão de como o profissional de design e arquitetura, no momento da concepção do projeto, poderá superar as barreiras físicas e sensoriais que o espaço poderá oferecer.

A fim de obter um pensamento linear teórico pautado em informações preexistentes, o método de pesquisa foi baseado na revisão bibliográfica de artigos e literatura acerca do tema. Buscou-se a compilação de conhecimentos das áreas de turismo de experiência e design universal. O livro de Neto e Gaeta (2010) foi utilizado como orientador do tema turismo de experiência. Ainda relacionado ao mote, textos do livro digital de Shimosakai (2010), foram consultados. Referente ao design universal utilizou-se como base teórica as obras de Bartalotti (2006), e Cambiaghi (2012). Além disso, foi utilizada a recente pesquisa elaborada pelo Ministério do Turismo, "Estudo do Perfil de Turistas - Pessoas com deficiência". Assim como também a NBR 9050 (ABNT, 2004), que dispõe sobre acessibilidade em edificações, a Convenção da ONU sobre os direitos da pessoa com deficiência e o Decreto-lei 5296, de dezembro de 2004. Todos esses conhecimentos foram reunidos a fim de justificar e elaborar a defesa do tema em questão: a relação necessária entre o turismo de experiência e os aspectos sensoriais do ambiente.

A produção literária e acadêmica acerca dos temas design universal, turismo de experiência e aspectos sensoriais do espaço vêm sendo cada vez mais abordados. Porém, nota-se que ainda não há a discussão das três temáticas reunidas. Os espaços de hospedagem contemporâneos devem possuir a capacidade de atender a uma demanda recente de viajantes que possuem algum tipo de deficiência. Com essa demanda, surge também a necessidade de se projetar - ou readequar espaços -, a fim de que seus usuários desfrutem dele em sua totalidade. Não se trata apenas de aspectos físico-espaciais, que são uma obrigação legislatória, mas da capacidade que o espaço possui de fornecer informações sensoriais ao seu usuário.

É quando a temática do turismo de experiência entra para a tríade. Os viajantes buscam, cada vez mais, novas experiências em seus passeios, e o espaço de acolhimento e de infraestrutura adotados são, em sua maioria, os espaços de hospedagem. São nos hotéis, pousadas e outros que o viajante se hospeda e passa boa parte dos momentos daquela viagem. Esses lugares são responsáveis por oferecer - ou não - ao usuário experiências e informações que poderão definir seu grau de satisfação com aquele momento de descanso ou lazer.

\subsection{Breves considerações sobre design universal e turismo de experiência}

De acordo com Cambiaghi (2012), durante a Idade Média, a pessoa com deficiência era vista como uma pecadora e, por isso, castigada por Deus com a deficiência. A sociedade medieval, então, isolava essa parte da população. 0 pensamento humano foi evoluindo de maneira lenta e gradativa em prol da inserção da pessoa com deficiência. No século XX, começou-se a pensar em medidas assistencialistas, de modo a tratar sua condição como doença. A década de 1970 foi marcante na busca de melhor entendimento da pessoa com deficiência e sua inserção na sociedade, com a Declaração dos Direitos da Pessoa Deficiente. Alguns anos depois a reclassificação da pessoa com deficiência, excluindo-a do Código Internacional de Doenças (CID). No Brasil, em 2009, promulgou-se a Convenção Internacional das Pessoas com Deficiência. Marco nacional importante também foi a criação das normas 
técnicas da NBR 9050 (ABNT, 2004), que normatizaram a acessibilidade a edificações, mobiliário, espaços e equipamentos urbanos, em 2004.

Ao abolir-se o conceito de integração - no qual a pessoa com deficiência deve se adaptar a um meio já construído - e utilizar-se do termo inclusão (Convenção da Guatemala ${ }^{2}$ ) começa-se a entender que o meio ou produto é que não estão adaptados à pessoa com deficiência, e não o contrário. O conceito de Desenho Universal já é utilizado desde a década de 1980, com Michael Bednar ${ }^{3}$, mas a expressão universal design teve sua origem nos Estados Unidos, com Ron Mace ${ }^{4}$. Desenho universal, ou design universal, é a prática de conceber e projetar espaços e produtos que possam ser utilizados pelo maior número de pessoas possível, sejam elas deficientes físicos, crianças, idosos, mulheres, estrangeiros, pessoas com dificuldades cognitivas, mães com carrinho de bebê ou outros. Para regulamentar o termo universal design, foram elaborados sete princípios, que são eles:

1. Uso equitativo: todos os usuários devem conseguir utilizar o produto ou espaço, sem distinguir ou segregar grupos de pessoas;

2. Flexibilidade no uso: o uso não deve se ater apenas a um grupo específico de pessoas (destro ou canhoto, por exemplo), mas permitir adaptar-se à utilização;

3. Uso simples e intuitivo: sua utilização deve evitar ao máximo o emprego de elementos complexos, facilitando a compreensão de todos, independentemente de suas capacidades;

4. Informação perceptível: a informação disponibilizada deve ser de fácil captação pelo usuário;

5. Tolerância ao erro: deve-se sempre minimizar as consequências de ações adversas do produto, a fim de manter a segurança do usuário;

6. Baixo esforço físico: o produto ou espaço deve ser utilizado de forma confortável, de maneira a evitar a fadiga;

7. Tamanho e espaço para aproximação e uso: o usuário deverá sempre conseguir se aproximar e manipular o produto ou espaço, independentemente de sua forma ou condição física.

O design universal, portanto, não é apenas uma ferramenta à disposição do profissional, mas, sim, um modo de projetar e pensar humanístico que não exclui ou cria grupos de minorias, mas, pelo contrário, busca atender ao maior número de usuários possível.

O ser humano é feito de memórias que se refletem em sua vida na forma de experiências, sejam elas boas ou ruins. Essas experiências estão presentes em todos os momentos da vida do homem, em seu cotidiano ou em situações externas a ele.

Hoje, os consumidores apresentam maior seletividade em relação aos serviços que consomem e aos produtos que adquirem, gerando uma demanda pela intensificação das 'experiências' como uma das formas de satisfação pessoal e profissional (NETO, 2010, p. 13).

\footnotetext{
${ }^{2}$ CAMBIAGHI, Silvana. Desenho Universal - métodos e técnicas para arquitetos e urbanistas. São Paulo: Senac São Paulo, 2012.

${ }^{3}$ BEDNAR, 1977 apud CAMBIAGHI, 2012, p.74.

${ }^{4}$ MACE, 1991 apud CAMBIAGHI, 2012, p.73.
} 
$O$ ato de viajar para o homem, tido na antiguidade como uma aventura perigosa ${ }^{5}$, hoje possui um conceito relacionado à socialização, experiência de vida. A inserção do homem num sistema de horas de trabalho semanal cíclica gera uma necessidade, muitas vezes latente, de escape - ou quebra - do cotidiano. A intenção da fuga dessa linearidade imposta é, muitas vezes, expressa no ato de viajar em busca de novas experiências.

A experiência é um aspecto extremamente complexo e relativo, por se tratar de questões psicológicas profundas, mas que, ao mesmo tempo, é inerente e pertencente a todo ser humano. Para se qualificar corretamente o turismo de experiência, deve-se levar em conta que a viagem tem que acrescentar algo a seu viajante, seja um aprendizado, um momento de felicidade, o contato com uma nova cultura ou uma experiência estética. MACIEL encara essa realidade do turismo de experiência como um aspecto estético-sensorial, que eleva o sujeito a altos níveis de sentimentos e emoções ${ }^{6}$.

A experiência que se busca é uma passagem individual, um esforço multissensorial que envolve tanto os sentidos da pessoa que busca a experiência, quanto a presença, o recorte da temporalidade e do sentido da sua existência (MACIEL, 2010 in NETTO e GAETA, 2010, p.66).

Mais que agregar valor a um cotidiano linear, ou à vida de modo geral, a procura pela experiência é a busca pelo autoconhecimento, por momentos que fazem o usuário ou viajante se redescobrir e reinventar. Vista desse modo, a experiência é um norteador de vida, ações e crenças do ser humano, podendo criar ou derrubar realidades e barreiras psicológicas. O turismo de experiência, por sua vez, ganha seu status de elevada importância à vida do homem, podendo conferir a ele momentos positivos únicos e inesquecíveis.

\subsection{Da legislação à inclusão social}

O pensamento do profissional projetista do espaço, infelizmente, ainda está longe de ser evoluído como se gostaria. Veem-se nas cidades brasileiras obras que acabaram de ser construídas sem os quesitos esperados de acessibilidade ou, quando muito, apenas o mínimo exigido por normas e leis. A acessibilidade hoje ainda não é vista como um pensamento holístico inerente ao momento do projeto, mas como uma ferramenta de projeto que pode ser utilizada ou não, como, por exemplo, uma rampa de acesso. Essa deve ser pensada como muito mais que isso; deve vir como um sentido de valor da sociedade, assim como a democracia ou a cidadania.

Espaços universais, que se propõem ser tangíveis e utilizáveis por todas as pessoas, estão lentamente se tornando uma tendência no cenário mundial. A viabilidade para que isso tenha chegado à contemporaneidade se deu por meio da percepção dos poderes públicos e organizações de expressão mundial dessa necessidade, e foi gradualmente sendo traduzida em forma de decretos e leis. Como, por exemplo, a Declaração dos Direitos das Pessoas Deficientes na Assembleia Geral da ONU, em 1975. Nesse momento da história, a deficiência física ainda era vista como uma doença - como citado anteriormente - e o pensamento era de integração, ou

\footnotetext{
${ }^{5}$ TRIGO, 2010 in NETTO e GAETA, 2010, p.21-22.

${ }^{6}$ MACIEL, 2010 in NETTO e GAETA, 2010, p.66
} 
seja, adaptar o sujeito ao ambiente, como é possível perceber no trecho da Declaração:

Tendo em vista a necessidade de prevenir deficiências físicas e mentais e de prestar assistência às pessoas deficientes para que elas possam desenvolver suas habilidades nos mais variados campos de atividades e para promover, portanto quanto possível, sua integração na vida normal (ONU, 1975).

Grandes evoluções de pensamento em relação a como a pessoa deficiente era vista na sociedade foram feitas, como, por exemplo, a criação da Resolução WHA54.21 em $2001^{7}$, que classifica o grau de funcionalidade do indivíduo. Seguindo a linha de evolução do pensamento humano em relação à pessoa com deficiência, em 2008, no documento da Convenção da ONU sobre os Direitos das Pessoas com Deficiência, o enriquecimento do modo de pensar foi marcante:

Reconhecendo que a deficiência é um conceito em evolução e que a deficiência resulta da interação entre pessoas com deficiência e as barreiras atitudinais e ambientais que impedem sua plena e efetiva participação na sociedade em igualdade de oportunidades com as demais pessoas (ONU, 2008).

Nesse momento, encara-se que o ambiente construído e as atitudes da sociedade em relação à pessoa com deficiência são fatores que podem definir o nível de inclusão a que esse indivíduo está sujeito. A responsabilidade de uma sociedade mais justa e inclusiva é vista na contemporaneidade como um dever de todos e, mais que nunca, dos responsáveis pela criação dos espaços de vivência.

No Brasil, o ponto marcante na luta pelos direitos das pessoas com deficiência foi o Decreto-Lei 5296 de 2004, que regulamenta as leis 10.048 e 10.098. Ambas dispõem sobre prioridade de atendimento à pessoa com deficiência e os critérios para promoção da acessibilidade, respectivamente. Um ponto específico do Decreto de muita importância para os profissionais de arquitetura e design é o que diz respeito à ABNT, que normatiza as regras de acessibilidade. A NBR 9050 (ABNT, 2004) dispõe sobre acessibilidade em edificações, mobiliário e equipamentos urbanos. Hoje, sua utilização é indispensável e as edificações atuais estão sujeitas a ela. Porém, há que se entender que a NBR 9050 é uma norma e, como tal, é uma ferramenta legislatória utilizada para regulamentação e criação de parâmetro de comparação. Deve-se admitir, portanto, que ela não seja suficiente para a concepção de espaços universais. Suas limitações se baseiam no fato de que ela é um instrumento regulador e, como tal, não consegue se tornar um modo de pensar democrático. E é por isso que cabe a todos, em especial aos profissionais do espaço, repensar seus métodos de trabalho e avaliar a situação à qual o projetar acessível "pela obrigação" pode nos levar. Quando as ferramentas normativas são somadas aos conceitos mais abstratos - e tão logo importantes - da arquitetura, o resultado é não menos que a construção de espaços democráticos, tangíveis a todo e qualquer usuário.

\subsection{O cenário atual do turismo acessível no Brasil}

${ }^{7}$ CAMBIAGHI, Silvana. Desenho Universal - métodos e técnicas para arquitetos e urbanistas. São Paulo: Senac São Paulo, 2012. p.25. 
De acordo com Censo realizado pelo Instituto de Geografia e Estatística IBGE em 2010, o número de pessoas com deficiência supera os 45 milhões (aproximadamente $24 \%$ da população brasileira). Somado a isso, há também $7,4 \%$ de idosos, que representam 14 milhões de pessoas. Pessoas que, antes, eram "desenganadas" pelos médicos e que, hoje, possuem recursos de sobrevivência e a expectativa de vida cada vez mais alta são parte desse contingente. Considerando os atuais desenvolvimentos da medicina contemporânea, que crescem exponencialmente, esses números tendem a aumentar. Tendo em vista que a melhor qualidade de vida das pessoas com o apoio médico tecnológico é uma tendência, devese pensar tão logo em como fornecer isso às pessoas com deficiência. $E$ a maneira discutida neste trabalho é o turismo. Além de ser uma atividade econômica de importância e possuir um papel social muito grande para as cidades receptoras, o turismo é um modo que o indivíduo, imerso em seu cotidiano, encontra para relaxar e se divertir. Pensando em todo esse panorama apresentado, a criação de hospedagens acessíveis a pessoas com deficiência deve ser uma tônica.

Embasado nos dados do Censo do IBGE, na Convenção sobre os Direitos da Pessoa com Deficiência e no Decreto no 6.949 de 2009 (diz sobre a participação das pessoas com deficiência na vida cultural, lazer e esportivas da sociedade), o Ministério do Turismo realizou, em 2013, o "Estudo do Perfil de Turistas - Pessoas com Deficiência". O documento trata de uma pesquisa qualitativa de pessoas com diversas deficiências, separadas em grupos por estados. A metodologia utilizada foi a entrevista, com perguntas pré-determinadas pelos entrevistadores de todos os estados. Dentro da pesquisa, foi possível perceber um dado que corrobora ainda mais a necessidade de criação de espaços de hospedagem acessíveis: a maioria dos entrevistados, apesar de sua deficiência - ou o grau a que estão submetidos -, possuem uma vida social ativa. Dentre os aspectos pesquisados, destacam-se os motivos que levam a pessoa a viajar e, assim como todos os outros viajantes, variam desde "visitar um familiar" até "viagem de negócios". Outro ponto citado por muitos entrevistados foi a falta de informação ou informação incorreta acerca da acessibilidade existente no local de hospedagem. Na conclusão do relatório, o ponto mais relevante para este artigo é o significado que o ato de viajar possui na vida da pessoa com deficiência.

\footnotetext{
A importância que é dada às viagens indica que, além de todos os fatores motivacionais já citados, existe também um sentimento de superação, liberdade e autonomia que o ato de viajar suscita nas pessoas com deficiência ouvidas (MINISTÉRIO DO TURISMO, 2013, p. 54).
}

Uma reclamação constante dos entrevistados é a falta de acessibilidade real dentro dos espaços de hospedagem. Muitas vezes, os hotéis e pousadas buscam soluções paliativas para adequar o espaço, porém, são medidas rasas, que não extinguem verdadeiramente as barreiras arquitetônicas.

O mercado turístico deve se atentar a essa nova demanda que surge cada dia mais forte. As pessoas com deficiência e os idosos não ficam mais limitados à sobrevivência diária dentro de suas residências, mas buscam, como todo ser humano, qualidade de vida, diversão e lazer. É fato que alguns locais já acordaram para essa realidade adaptando seus espaços ou criando novos a fim de atender à demanda crescente de pessoas com necessidades especiais. Ainda que tardia e muito ampla, a 
ponto de ficar ligeiramente vaga, a pesquisa do Ministério do Turismo pode ser considerada como um ponto de partida para uma leitura do que ocorre hoje nos espaços de hospedagens brasileiros. Espaços esses criados sem o pensamento do design universal e que, quando adaptados, não chegam a atender as demandas reais que o problema impõe.

\subsection{Os aspectos sensoriais do espaço}

O nosso entendimento do mundo em que vivemos se dá por meio de um reflexo de interações entre os estímulos que recebemos e a nossa interpretação pessoal de cada um deles. Os espaços construídos, por sua vez, não fogem à regra e entram nesse jogo como emissores de estímulos sensoriais.

O olfato, tato, paladar, audição e visão são os cinco sentidos humanos que nos possibilitam captar as mensagens que o meio nos oferece. Biologicamente falando, o meio nos fornece uma informação, o corpo humano a recebe e logo a interpreta quente e frio, por exemplo. Mas, ao olhar mais a fundo a recepção dessas informações, vê-se que a percepção do meio é mais complexa do que apenas um canal de informações de mão única. Todos os seres humanos possuem uma experiência de vida única e intransferível. Cada um de seus sentidos, quando estimulados, lhes trará uma resposta diferente, que varia de indivíduo para indivíduo. Uma determinada música para uma pessoa pode trazer lembranças boas de um momento passado, como também pode, em outro indivíduo, reavivar sentimentos indesejados. Esse foi um exemplo citado para o sentido da audição, e isso ocorre de maneira concomitante com a visão, tato, paladar e olfato.

A ausência de um sentido não significa perda - no sentido mais amplo da palavra - de percepção. O conjunto de interpretações possíveis dentro daquilo que sentimos é infinito, e o elemento facilitador disso é a imaginação. Enquanto o indivíduo tiver capacidade de perceber, não importa de qual maneira, haverá compreensão do espaço, ainda que intuitiva. Portanto, deve-se entender que todo objeto ou espaço é passível de interpretação pelos cinco sentidos humanos e, logo, podem ser tangíveis a todos, independentemente de um desses estar ausente. O papel do arquiteto e do designer nessa história é compreender que todo objeto e espaço são um emissor, como bem defende ALCANTARA; ARAÚJO; RHEIGANTZ (2004) no artigo "Os sentidos humanos e a construção do lugar - Em busca do caminho do meio para o desenho universal".

\footnotetext{
Desconhecendo a contribuição das ciências cognitivas, os arquitetos preocupam-se com as questões materiais, estéticas e com a geometria dos seus espaços, descuidando das questões relacionadas com as sensações, percepções, formações mentais e a consciência dos usuários. Em geral, não atentam para a influência das formas visíveis, sons, odores, sabores, coisas tangíveis ou palpáveis sobre os "objetos" da mente - pensamentos, ideias e concepções - nas reações das pessoas em sua interação com o ambiente (ALCANTARA; ARAÚJO; RHEIGANTZ, 2004, p.2).
}

Estudos foram elaborados acerca do tema por vários pesquisadores, no qual a importância das cores no ambiente foi constatada por pessoas cegas ou de baixa visão. Buscar explorar ao máximo os sentidos humanos nos espaços construídos é dever do projetista do espaço, tendo em vista sua comprovação e eficácia. Isso se torna uma medida de concepção de projeto humanizada, uma vez que todos terão "acesso" a 
esse ambiente ou objeto mesmo que não possuam algum de seus sentidos. A riqueza de informações obtida de um espaço varia, então, da compreensão que o projetista tem de sua responsabilidade perante o projeto do ambiente, podendo conferir a ele alto nível de dados sensoriais ou não. Tão logo seu caráter de projeto universal, ou não.

\subsection{Design universal, aspectos sensoriais do espaço e turismo de experiência}

Tendo em vista todos os temas que já foram discorridos neste estudo, fica o questionamento sobre qual a relação entre o turismo de experiência para todos e os aspectos sensoriais do ambiente.

Voltando ao conceito de turismo de experiência, temos, resumidamente, que é um turismo feito com o objetivo de acréscimo de cultura, conhecimento ou experiências estéticas. Independentemente do objetivo de viagem do usuário, o mínimo que se deve exigir são edificações - hotéis, pousadas, albergues e outras - que sejam acessíveis a pessoas com necessidades especiais e estejam dentro das normas exigidas por lei. Mesmo que se saiba que a realidade não é essa - como colocado anteriormente neste artigo - , continuemos com a linha de pensamento proposta. Dando um passo à frente e considerando ainda que o espaço de hospedagem fosse concebido de forma eficiente, seguindo todos os sete princípios do design universal, e que, de uma maneira funcional, a edificação é satisfatória, ainda assim não se é capaz de dizer que o viajante terá uma experiência turística naquele local. E o que definiria isso? Como tornar, portanto, uma viagem corriqueira em um turismo de experiência completo, do começo ao fim, inclusive no espaço de hospedagem? E a pergunta motor deste artigo, sobre a relação entre turismo de experiência para todos e os aspectos sensoriais do ambiente, é necessária?

O viajante, assim que se decide por realizar um turismo de experiência, busca sair de sua vivência comum e cotidiana em busca de uma nova vivência. As expectativas que estão entremeadas em todo o processo são das mais diversas: o que encontrarei ao chegar lá, como será o hotel, como vão me atender, e tantos outros questionamentos surgirão. Para o turista com deficiência, os questionamentos e expectativas tendem a ser mais intensos. As preocupações, além daquelas citadas, possuem um fundo mais sério, que diz respeito à possibilidade de se viabilizar a sua hospedagem com segurança. As informações incompletas e desencontradas, fornecidas pelos hotéis e pousadas, as quais foram citadas na pesquisa do Ministério do Turismo, levam o turista a uma falta de confiança sobre a, de fato, acessibilidade do local. Para o turista com deficiência, chegar a um destino que não pode recebê-lo de forma adequada é um fato, no mínimo, frustrante. Até aí, o turismo de experiência já não pode ser realizado em sua forma completa, pois, sempre que o viajante chegar ao seu local de hospedagem, não haverá estrutura para recebê-lo, portanto, sua experiência do local será neutra ou negativa. Além dos aspectos físicos do ambiente, a acessibilidade visível, deve-se levar em conta a acessibilidade invisível. O visível se resume a ferramentas de acessibilidade que possibilitem a utilização do espaço ou equipamento por todos. Por exemplo, a presença de rampas com inclinação adequada, guarda-corpo, sinalização, mapas táteis, Braille, barras de apoio nos banheiros e outros elementos necessários à boa acessibilidade do local. É como se a acessibilidade visível fosse, em parte, a adoção dos parâmetros das normas vigentes relativas à 
acessibilidade. A acessibilidade visível é, portanto, a parte física da acessibilidade, aquilo que podemos normatizar e regulamentar, criando parâmetros para tal.

Já a acessibilidade invisível se trata de aspectos não táteis ou normatizáveis. Ela possui duas vertentes, a do atendimento ao cliente e a dos aspectos sensoriais do ambiente. Ainda que o que nos interesse neste estudo seja a avaliação da qualidade sensorial que o ambiente pode trazer, é importante também ressaltar o fator atendimento ao cliente. Voltando à etapa em que o turista busca informações sobre sua viagem - que, por si só, já se caracteriza em uma experiência de criar uma expectativa -, é importante que essas informações sejam corretas acerca do que o local de hospedagem oferece. Para o turista com deficiência, a confiabilidade desses dados pode significar a estadia ou não naquele local. Seguindo adiante, ao chegar ao hotel, é importante que todos sejam tratados de maneira sensível, de modo que a pessoa com deficiência não seja excluída ou superprotegida. $O$ atendimento deve ser universal - que não se entenda universal como igual a todos -, de modo que respeite e compreenda as limitações e as capacidades de cada hóspede.

Dos aspectos relativos ao espaço, voltaremos nosso olhar à capacidade que os objetos e o meio possuem de emitir informações além de nossa percepção visível. Deve-se levar em conta que o ser humano é capaz de formar "imagens" mentais dos espaços com a influência dos seus cinco sentidos e, mesmo que lhe falte algum desses, ainda assim, a "imagem" será criada. A imagem nada mais é que o conjunto de sentidos oferecidos pelo meio.

A frase "A experiência do olhar, apesar de ser a primeira experiência de um viajante, se tida como a única, é incompleta.", dita em uma palestra sobre turismo acessível por uma palestrante com baixa visão, Renata (2013), pode ser vista como um acordar para os arquitetos e designers. Coloca-se nessa fala que o espaço é muito mais que um conjunto de componentes ordenados de maneira visual. Tanto que se diz que o olhar é apenas uma maneira de compreender o meio. Levando isso para os outros sentidos, cada um deles é uma forma única de interpretação, mas que, se considerados em conjunto, possibilitam uma experiência holística de cultura, relação com o espaço e experiência estética. Portanto, temos que o turismo de experiência só se torna completo quando há uma experiência a ser vivida em todas as esferas, tátil, visual, olfativa, palatal e auditiva.

O espaço, por sua vez, é capaz de fornecer todas essas informações ao mesmo tempo, com intensidades diferentes. O projetista é o responsável por criar essas ambiências sensoriais que farão a diferença para que se tenha uma experiência no local de hospedagem. O viajante que busca o turismo de experiência quer imergir em novas sensações e vivências, e quando o espaço - no caso, o local de hospedagem não fornece isso, a experiência como um todo é sempre interrompida. Toda vez que o viajante chega ao seu hotel, a fantasia, o aprendizado, a experiência estética acabam, justamente por ele estar inserido em um ambiente estéril, sem informações sensoriais. Além desse aspecto de experiência que o meio construído pode trazer ao usuário, há também o lado social de se pensar em espaços de hospedagem sensoriais.

De acordo com Renata (2013), não se deve considerar apenas um sentido humano - a visão, por exemplo - como método de apreensão do espaço. Quando sugerimos que o espaço construído é feito apenas para os olhos, estamos excluindo todas as pessoas que não possuem esse sentido de apreender o espaço. E assim sucessivamente, com as pessoas com deficiência auditiva, cognitiva, física e outras. Um 
espaço concebido para todos deve fornecer aos seus usuários todas as informações possíveis para que a abrangência de seus dados seja ampliada, criando, assim, um espaço universal. $E$ isso se reflete para o turismo de experiência. Afinal, como criar uma experiência marcante e holística se o espaço de hospedagem é neutro e sem informações? Por isso, a importância de criação de espaços universais e sensoriais no turismo de experiência. Sendo assim, a tríade turismo de experiência, design universal e aspectos sensoriais do ambiente só é completa, abrangente e holística quando tratadas de maneira integrada e interdependente.

Ao profissional responsável pelo projeto e concepção do espaço cabe a imensa responsabilidade de criar espaços detentores de informações sensoriais. Esses dados podem estar implícitos de várias maneiras dentro de um ambiente: na cor que se propõe uma parede, na intensidade de luminosidade, na forma que se dá a um ambiente. Na vegetação - seus perfumes, suas sombras e sons - a que o hóspede estará submetido. No som de pássaros, água corrente, peixes ou uma música específica. Nos odores que vêm de uma cozinha, um fogão à lenha ou um determinado perfume. Nos enquadramentos das paisagens e tantos outros elementos sensoriais que o profissional tem a seu favor. Com isso, a arquitetura vai além de sua função de hospedar, ou abrigar - emprego primeiro da arquitetura -, mas se coloca como elemento social em prol de uma sociedade mais humana e acessível.

\section{CONCLUSÃO}

Colocou-se neste artigo a importância de projetar espaços de hospedagens sensoriais a fim de se obter um turismo de experiência completo. Todavia, não se esperou com este o esgotamento dos três temas arguidos: design universal, turismo de experiência e aspectos sensoriais do ambiente. Apenas buscou-se colocar em pauta uma tríade que se refere não só aos temas que a eles corresponda, mas também à humanização da arquitetura e design de espaços. Foi visto que a relação entre o turismo de experiência para todos e os aspectos sensoriais do ambiente é de grande valor quando se busca resultados arquitetônicos e experienciais positivos, que abranjam a todos. E a mensagem que se coloca é a de que os profissionais, arquitetos e designers possuem essencial papel na criação de espaços mais humanos e sensoriais. É também deles a responsabilidade pelo desempenho eficaz do turismo de experiência para todos, uma vez que eles são os encarregados por projetar o ambiente construído e, tão logo, salientar os aspectos intrínsecos do local e criar novos marcadores sensoriais. Essas medidas são responsáveis para que cada microambiente presente no espaço se destaque e provoque sensações sinestésicas diferentes no usuário. Cada sentimento desses resulta em uma percepção individualizada do espaço, e essa ideia só tende a se tornar mais legítima à medida que são considerados usuários portadores de deficiência motora, visual, auditiva, intelectual ou cognitiva. O ambiente traz consigo marcadores sensoriais que, quando trabalhados em prol da melhor percepção do sítio, só tendem a ressaltar os atributos físicos da arquitetura do local e, logo, as experiências vividas pelo usuário. O profissional deve sempre estar em busca de uma arquitetura acessível e, especialmente, tangível a todos, que seja capaz de provocar no usuário experiências agradáveis e memoráveis. 


\section{REFERÊNCIAS}

ALCANTARA, Denise de; ARAÚJO, Mônica Queiroz; RHEINGANTZ, Paulo Afonso. Os sentidos humanos e a construção do lugar - Em busca do caminho do meio para o desenho universal. 2004. 06f. Artigo Publicado nos Anais do Seminário Acessibilidade no Cotidiano (CD-Rom) - Rio de Janeiro.

ASSOCIAÇÃO BRASILEIRA DE NORMAS TÉCNICAS. NBR 9050: 2004 “Acessibilidade de pessoas portadoras de deficiências a edificações, espaço, mobiliário e equipamentos urbanos". Rio de Janeiro, 2004.

BARBOSA, Marcos Aguiar. Hospedagem com espaços acessíveis - A arquitetura e o negócio hoteleiro.

BARTALOTTI, Celina Camargo. Inclusão das pessoas com deficiência: utopia ou possibilidade?. São Paulo: Paulus, 2006.

BRASIL. Decreto no 5.296, de 2 de dezembro de 2004. Regulamenta as Leis nos 10.048, de 8 de novembro de 2000, que dá prioridade de atendimento às pessoas que especifica, e 10.098, de 19 de dezembro de 2000, que estabelece normas gerais e critérios básicos para a promoção da acessibilidade das pessoas portadoras de deficiência ou com mobilidade reduzida, e dá outras providências.

CAMBIAGHI, Silvana. Desenho Universal - métodos e técnicas para arquitetos e urbanistas. São Paulo: Senac São Paulo, 2012.

GUIMARÃES, Marcelo Pinto. A Acessibilidade da Sociedade Inclusiva. Website Adaptse. Disponível em: <http://pages.adaptse.org/1727<. Acesso em 16 jan. 2014

GUIMARÃES, Marcelo Pinto. Acessibilidade: diretriz para a inclusão. Website Adaptse. Disponível em: <http://pages.adaptse.org/1723<. Acesso em 16 jan. 2014

GUIMARÃES, Marcelo Pinto. Uma abordagem holística na prática do Design Universal. 2007. 19f. Artigo - Universidade Federal de Minas Gerais. Laboratório ADAPTSE Escola de Arquitetura.

MINISTÉRIO DO TURISMO, 2013. Estudo do perfil de turistas - Pessoas com Deficiência. Documento técnico, 2013.

NETO, Alexandre Panosso e GAETA, Cecília. Turismo de experiência. São Paulo: Senac São Paulo, 2010.

ONU. Assembleia Geral da Organização das Nações Unidas - Declaração dos direitos das pessoas deficientes, de 09 de dezembro de 1975. Portal MEC. Disponível em: <http://portal.mec.gov.br/seesp/arquivos/pdf/dec def.pdf>. Acesso em: 19 fev. 2014

Renata. Palestra na X Semana do Curso de Turismo da UFMG - Empreendedorismo e Turismo. 2013.

SHIMOSAKAI, Ricardo. Acessibilidade e Inclusão no Turismo. In: Turismo Adaptado, São Paulo, jan.2010. 1 DVD-R.

SHIMOSAKAI, Ricardo. Palestra na X Semana do Curso de Turismo da UfMG Empreendedorismo e Turismo. 2013. 